\title{
Fabrication and Testing of CERMET Fuel Materials for Nuclear Thermal Propulsion
}

\author{
Robert R. Hickman, Jeramie W. Broadway, and Omar R. Mireles \\ NASA Marshall Space Flight Center, Huntsville, AL, 35802
}

\begin{abstract}
A first generation Nuclear Cryogenic Propulsion Stage (NCPS) based on Nuclear Thermal Propulsion (NTP) is currently being developed for Advanced Space Exploration Systems. The overall goal of the project is to address critical NTP technology challenges and programmatic issues to establish confidence in the affordability and viability of NTP systems. The current technology roadmap for NTP identifies the development of a robust fuel form as a critical near term need. The lack of a qualified nuclear fuel is a significant technical risk that will require a considerable fraction of program resources to mitigate. Due to these risks and the cost for qualification, the development and selection of a primary fuel must begin prior to Authority to Proceed (ATP) for a specific mission. The fuel development is a progressive approach to incrementally reduce risk, converge the fuel materials, and mature the design and fabrication process of the fuel element. A key objective of the current project is to advance the maturity of CERMET fuels. The work includes fuel processing development and characterization, fuel specimen hot hydrogen screening, and prototypic fuel element testing. Early fuel materials development is critical to help validate requirements and fuel performance. The purpose of this paper is to provide an overview and status of the work at Marshall Space Flight Center (MSFC).
\end{abstract}

\section{Introduction}

$\mathrm{N}$ ASA'S Nuclear Cryogenic Propulsion Stage (NCPS) project was initiated in October, 2011, with the goal of assessing the affordability and viability of Nuclear Thermal Propulsion (NTP). Many believe that NTP is the best near term propulsion option for crew and cargo missions to the Moon, near earth objects, Mars and other deep space destinations. The belief is due to increased performance and lower cost (fewer launches) as compared to current chemical rockets. The feasibility of NTP was clearly established in the 1960's during the joint NASA and Atomic Energy Commission Rover/NERVA (Nuclear Engine for Rocket Vehicle Application) Program ${ }^{1}$. Since then, the potential application of NTP for human related Mars transportation has been studied extensively. However, many questions concerning the development and affordability still remain. As part of the current NCPS Project, the Marshall Space Flight Center (MSFC) is conducting a multi-tasked effort to support development of an NTP engine system. The focus of the effort is to define a comprehensive development strategy, identify key needs and risks, and build a foundation for enabling technologies. Key elements of the project include 1) Pre-conceptual design of the NCPS and architecture integration; 2) Development of a High Power ( 1 MW input) Nuclear Thermal Rocket Element Environmental Simulator (NTREES); 3) NCPS Fuel Design and Testing; 4) NCPS Fuels Testing in NTREES; 5) Affordable NCPS Development and Qualification Strategy; and 6) Second Generation NCPS Concepts.

A key enabling technology for an NCPS system is the fabrication of a stable high temperature nuclear fuel form. Although much of the technology was demonstrated during previous programs, there are currently no qualified fuel materials or processes. Early fuel materials development is critical to validate requirements and minimize technical, cost, and schedule risks for future programs. The objective of the NCPS Fuel Design and Fabrication task is to demonstrate materials and process technologies for manufacturing robust, full-scale CERMET and graphite fuel elements. The development will be a phased approach to recapture key technologies and produce quality fuels. Samples will then be tested in flowing hot hydrogen to understand processing and performance relationships. As part of this demonstration task, a final full scale element test will be performed to validate robust designs. These demonstrations are necessary to enable a future fuel material down select and a potential follow on ground test project. The purpose of this paper is to provide an overview and status of the fabrication and testing of CERMET fuels at MSFC. 


\section{CERMET Fuel Materials and Processes}

CERMET fuels consist of ceramic fuel particles such as uranium dioxide $\left(\mathrm{UO}_{2}\right)$ embedded in a metal matrix, which is typically tungsten (W) due to a high melting point and excellent compatibility with hot hydrogen. CERMET samples subjected to long term hot flowing hydrogen, irradiation, and transient reactor testing during the GE-710 and ANL programs showed good robustness and retention of fuel particles ${ }^{2}$. CERMETS are typically formed by consolidation or densification of powders using Powder Metallurgy (PM) processes. Complex tungsten based CERMETS with hafnium nitride $(\mathrm{HfN})$ and zirconium oxide $\left(\mathrm{ZrO}_{2}\right)$ surrogate ceramic particles have been fabricated to near $100 \%$ density at MSFC using Hot Isostatic Press (HIP) techniques. During HIP, the CERMET powders are consolidated in sacrificial containers at $2000^{\circ} \mathrm{C}$ and pressures up to $30 \mathrm{ksi}$. The HIP container design, powder size and shape, powder loading, sealing, and HIP processing parameters significantly affect the quality and repeatability of the final part. Figure 1 shows a typical CERMET microstructure and image of a net shape HIP consolidated part.
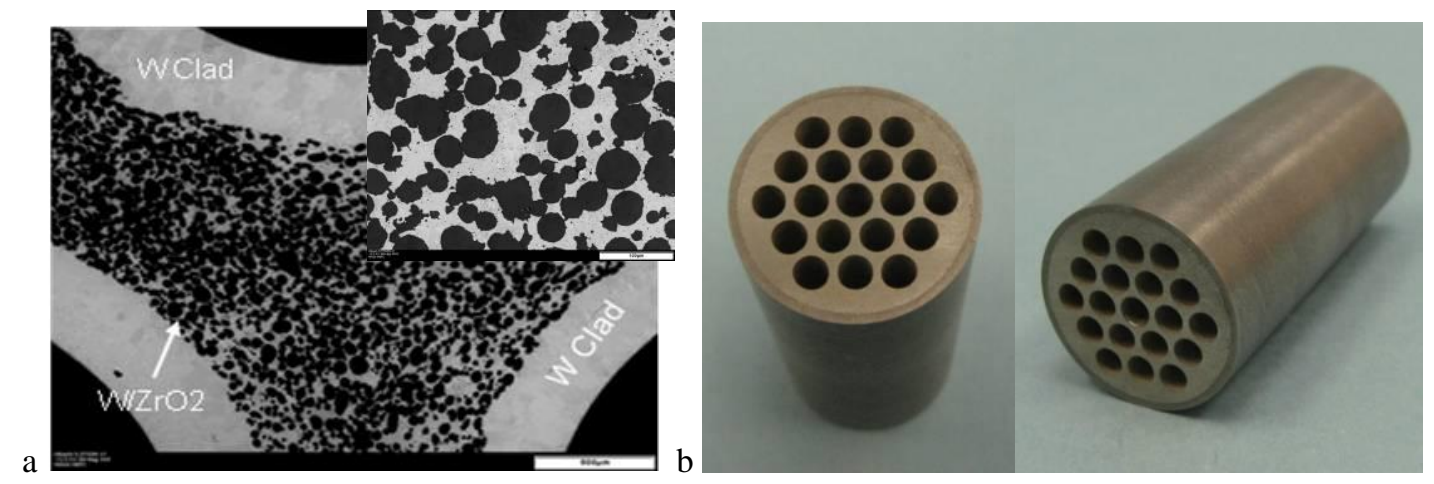

Figure 1. a) Micrograph of a W/60 vol\% $\mathrm{ZrO}_{2}$ CERMET with integral $\mathrm{W}$ claddings

b) Consolidated W/40 vol\% HfN CERMET sample.

An iterative approach is being used to sequentially demonstrate and optimize the materials and process technologies for fabrication of robust, full scale CERMET fuel elements. The elements will be based on the starting materials, compositions, microstructures, and fuel forms that were demonstrated on previous programs ${ }^{3}$, which includes the production of 10-200 micron (um) spherical $\mathrm{UO}_{2}$ particles, CVD tungsten coating of fuel particles, integral tungsten claddings on both the element OD and ID of cooling channels, and the addition of oxide stabilizers such as gadolinia $\left(\mathrm{Gd}_{2} \mathrm{O}_{3}\right)$. CERMETS with mono and mixed size fuel particles are also being fabricated for characterization and material property testing. $\mathrm{W}-\mathrm{UO}_{2}$ samples will then be tested in flowing hot hydrogen to understand processing and performance relationships. The list below provides a summary of the mechanisms and approaches that will be developed to demonstrate the performance of CERMET fuels.

Fuel loss from tungsten CERMETS involves one or more of the following mechanisms:

- Loss by vaporization of exposed and interconnected fuel particles

- Thermal decomposition of fuel/matrix and subsequent migration of products

- Diffusion through micro-pores and/or micro-cracks

- High vapor pressures exerted by impurities present in consolidated parts

- Differences in thermal expansion of tungsten and fuel particles

The materials and process approaches being studied to minimize or inhibit fuel loss are:

- Size of the fuel particles and resultant shape in the consolidated part

- Tungsten coating of spherical UO2 particles prior to consolidation

- Complete surface cladding with tungsten

- Addition of small amounts of fuel particle and matrix stabilization materials

\section{A. Spherical Uranium Dioxide (UO2) Feedstock}

A critical part of CERMET fuels fabrication is developing high quality, spherical $\mathrm{UO}_{2}$ feedstock. While no specific requirement exists for the desired particle sizes, information from historical $\mathrm{W}-\mathrm{UO}_{2}$ cermet programs suggest that the particles should range in size from 10-200 $\mu \mathrm{m}$. An initial search for current $\mathrm{UO}_{2}$ production 
capabilities has shown that existing vendors can produce spherical depleted and natural $\mathrm{UO}_{2}$ particles. However, the smallest sizes that can be acquired are approximately $100 \mu \mathrm{m}$ and the cost for procurement of those particles is very high. Possible acquisition options for purchasing spherical $\mathrm{UO}_{2}$ particles, along with the advantages and disadvantages of each, were evaluated by the integrated MSFC and DOE (Idaho National Laboratory and Oak Ridge National Laboratory) Fuels Development Team. The decision was made to purchase readily available material from the Y-12 Laboratory. The Y-12 laboratory currently has affordable methods of fabricating $\mathrm{UO}_{2}$ particles at approximately 100 um and larger. However, the $\mathrm{UO}_{2}$ particles are not spherical. Figure 2 shows examples of the feedstock that can be obtained from Y-12.
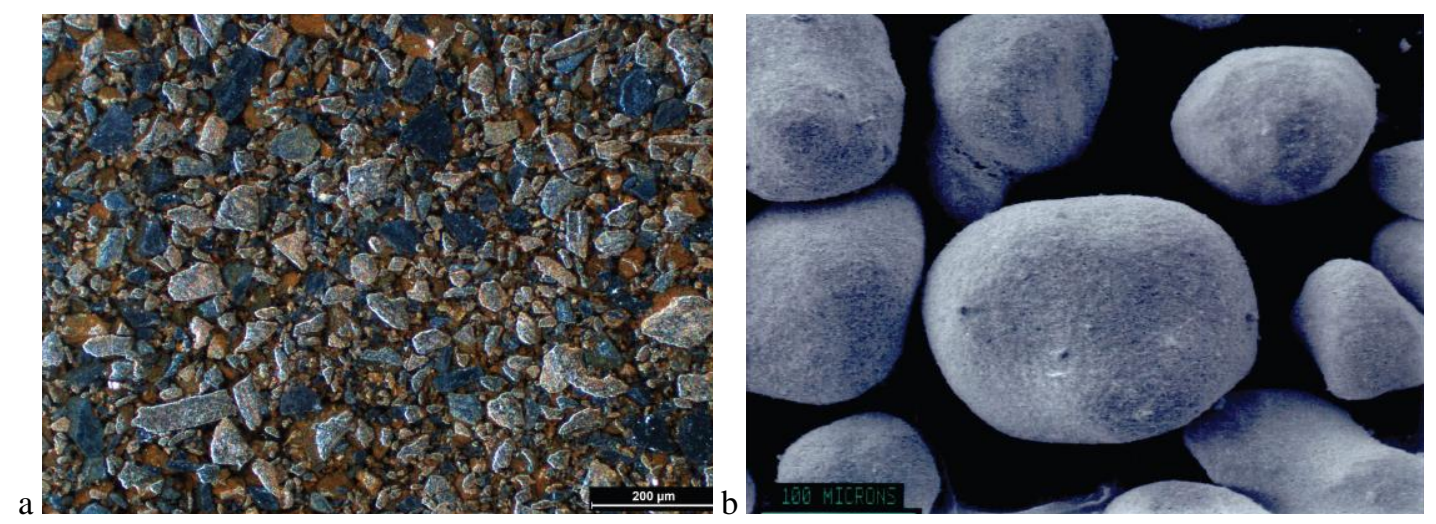

Figure 2. Pictures of $\mathrm{Y}-12 \mathrm{UO}_{2}$ feedstock: (a) $\mathrm{dUO}_{2}$ and (b) $\mathrm{nUO}_{2}$.

A Plasma Spheroidization System (PSS) was designed and assembled at MSFC to spheroidize the $\mathrm{UO}_{2}$ particles. MSFC has a rich history in the development of plasma spray coatings including a dedicated Thermal Spray Laboratory with various air and vacuum plasma spray systems. The PSS will spheroidize the particles by passing them through a plasma torch that is fully contained in a vacuum chamber. During processing, the particles are partially melted by the plasma, re-solidified to a spherical shape, and collected at the bottom of the chamber. The particles are be placed into sealed containers in a glove box prior to transferring to the PSS. The containers mate with the PSS system for inert processing and control of material.

\section{B. Chemical Vapor Deposition (CVD) Tungsten Coated $\mathrm{UO}_{2}$ Particles}

A fluidized bed chemical vapor deposition (CVD) process is being developed to pre-coat the $\mathrm{UO}_{2}$ with the tungsten matrix material. Coated particles are preferred for CERMETS with high volume percent fuel to improve the particle distribution. The tungsten coating prevents $\mathrm{UO}_{2}$ particle to particle contact, agglomeration, and coalescence during consolidation. CVD coatings also develop a columnar grain structure with a low grain boundary misorientation angle that prevents the deleterious build-up of hydrogen in the grain boundaries. The CVD process uses hydrogen reduction of tungsten hexachloride $\left(\mathrm{WCl}_{6}\right)$, which deposits on the $\mathrm{UO}_{2}$ particles in a fluidized bed. Figure 3 shows images of the MSFC CVD system and preliminary tungsten coated $\mathrm{ZrO}_{2}$ surrogate particles. Significant work has been performed to optimize the CVD reactor and sublimation process.
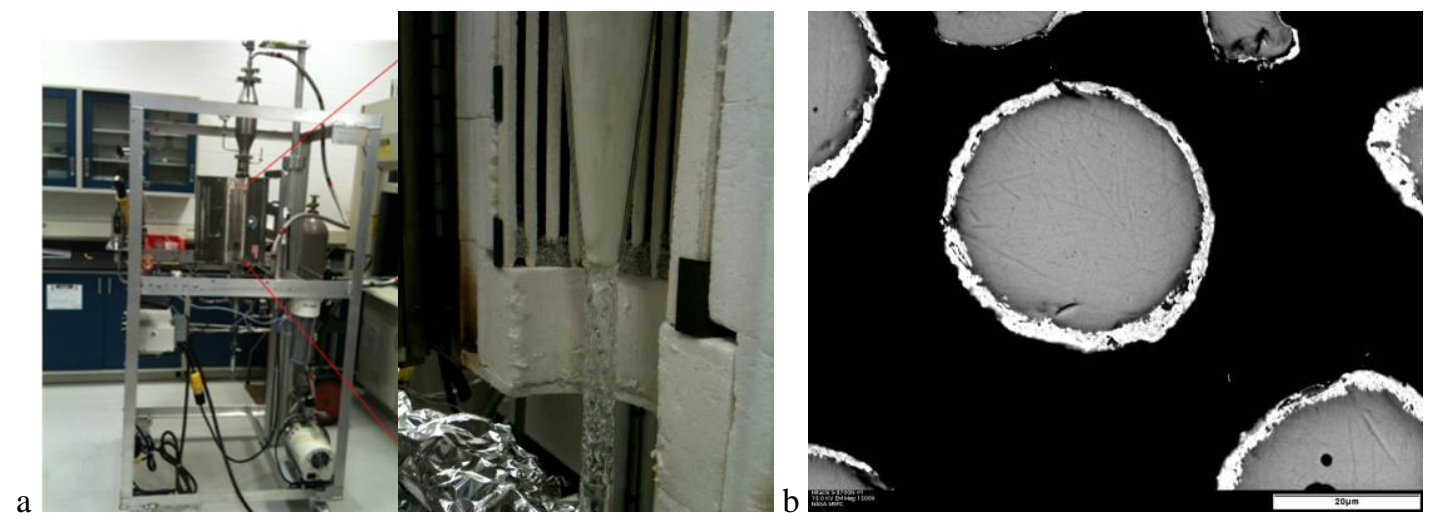

Figure 3. a) Fluidized Bed CVD System and b) Tungsten coated $\mathrm{ZrO}_{2}$ particles. 


\section{Hot Isostatic Press (HIP) Fabrication of Prototypical CERMET Elements}

Research at MSFC is also focused on developing fabrication processes for prototypical CERMET fuel elements. Although CERMETS were successfully tested on previous programs, fabrication techniques have not been demonstrated to full scale. Early development of prototypical fabrication techniques is required to demonstrate affordability, develop material specifications, and rapidly converge on design requirements. Figure 4 shows images of a 331 channel hexagonal fuel element sample during HIP fabrication. The fabrication process includes inert glovebox welding of niobium HIP can components, assembly of sacrificial mandrels in the can, powder filling, and vacuum closeout. After HIP consolidation, the sacrificial mandrels are preferentially removed using chemical etching. The hexagonal element was based on the ANL 2000MW CERMET reactor design, which is considered the most difficult configuration to fabricate. Figure 5 shows images of a 12" long 19-hole CERMET sample. The part had uniform shrinkage during HIP and good tolerance on the flow channel geometry. Current work is focused on fabricating full length (16.8” long), 61 channel hexagonal elements based the smaller ANL 200MW design.

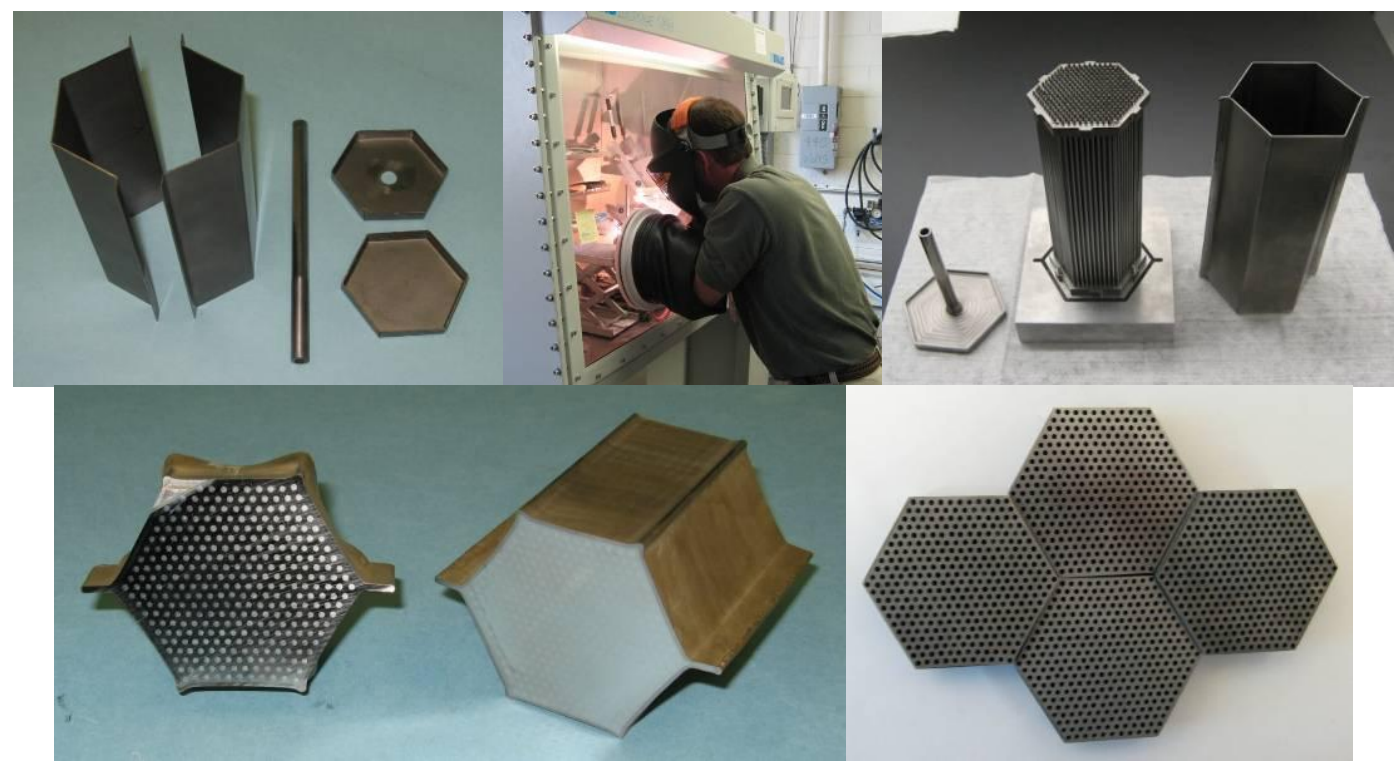

Figure 4. Images of a hexagonal fuel element sample during HIP fabrication.
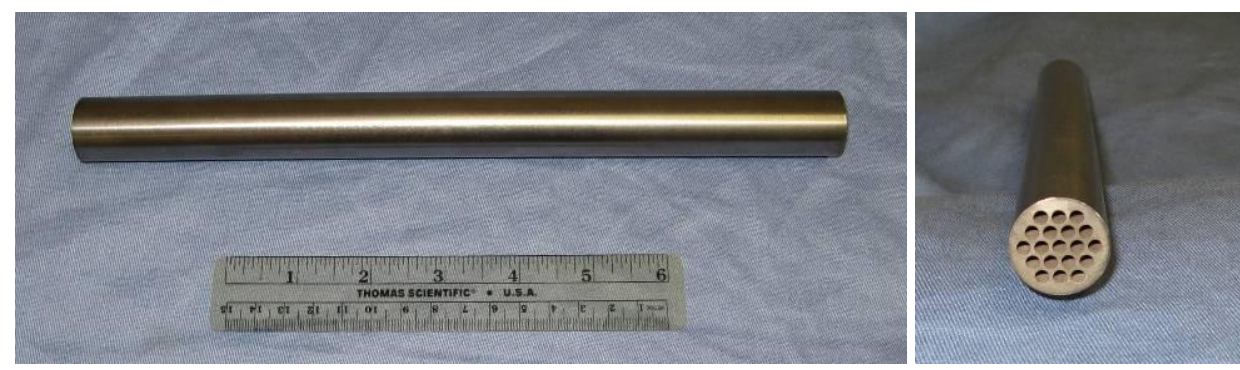

Figure 5. Images of a hexagonal fuel element sample during HIP fabrication.

\section{Hot Hydrogen Testing}

A critical obstacle to the development of an NCPS engine is the high-cost and safety/security concerns associated with developmental testing in nuclear environments. Previously, efforts at MSFC under NASA's Prometheus Program resulted in the development and demonstration of environmental simulators that are capable of subjecting fuel material samples and full scale elements to hot hydrogen. The purpose of this baseline testing capability is to enable low-cost screening of candidate materials, fabrication processes, and further validation of concepts/designs.

Hot hydrogen testing at MSFC will range from small subscale samples to near-prototypic full length fuel elements. A primary goal of the testing is to demonstrate adequate fuel performance and to increase confidence in fuel system designs (e.g. materials, coatings, geometries) prior to potential nuclear testing. CERMET samples will 
be thermal cycle tested in a flowing environment. Several iterations of testing will be performed to evaluate fuel mass loss impacts from density, microstructure, fuel particle size and shape, chemistry, claddings, particle coatings, and stabilizers. Initial subscale testing will be performed in the Compact Fuel Element Environmental Test (CFEET) system. The CFEET test samples will be approximately 0.5 " diameter x 1 " length for solid slug and prototypic 7 hole channel configurations. Testing of solid slugs will be performed to baseline performance prior to introducing geometric variables. Figure 6 shows images of the CFEET system and test sample.

The 7-hole channel configuration was chosen for CFEET screening to rapidly evaluate thermal cyclic affects on prototypic geometries from surface vaporization, diffusion/migration, and cracking. Testing has shown that fuel mass loss is significantly impacted by thermal cycling and geometry. The prototypical geometry will be much more susceptible to cracking induced migration and volatilization of the exposed fuel particles. The fuel materials and forms such as coated particles, claddings, and stabilizers being evaluated on this effort have all been demonstrated to control fuel migration and loss. The objective is to verify performance improvements of the various materials and processes prior to expensive full scale fabrication and testing. Post test analysis will include weight percent fuel loss, microscopy (SEM, EBSD, and EDS), and dimensional tolerance and cracking. After screening, full scale elements will be tested in the Nuclear Thermal Rocket Element Environmental Simulator (NTREES). The goal is to benchmark performance in NTREES for comparison to future materials and process improvements, alternate fabrication processes, and other fuel materials of interest. The iterative materials and process development, CFEET screening, and NTREES testing will continue through the FY12-14 NCPS effort with numerous subscale and full scale element testing milestones.
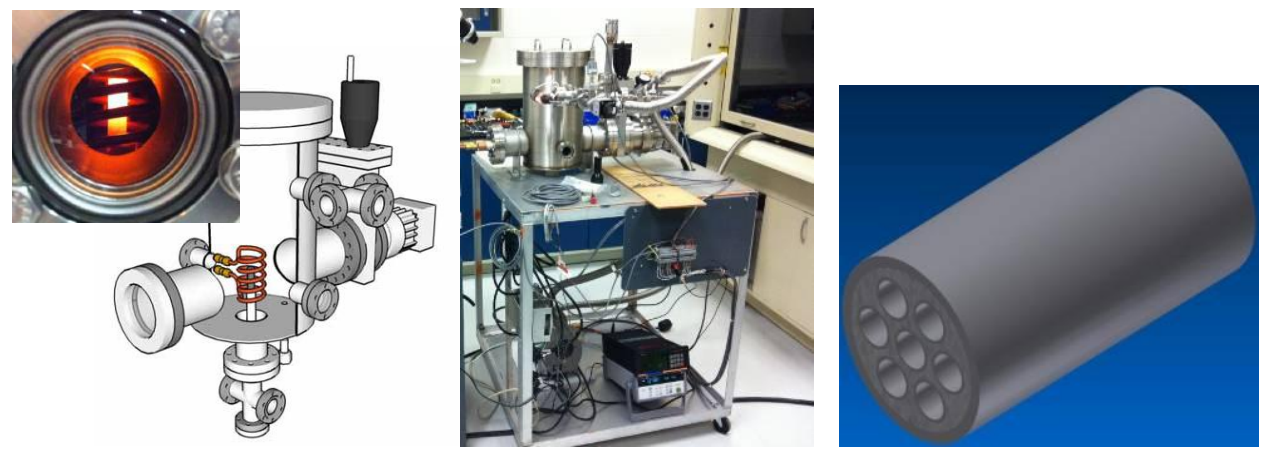

Figure 6: CFEET system and sample configuration

\section{Conclusion}

Development and fabrication of a stable high temperature fuel form is a critical need for future NTP systems. Due to the difficulty and safety concerns, non-nuclear development should be utilized as much as possible to reduce costs. A non-nuclear approach utilizes surrogate and depleted uranium samples to optimize fabrication processes and material properties. Recently, MSFC developed sub-scale and larger full size element test systems that are capable of subjecting materials to relevant reactor conditions. The current effort at MSFC is focused on the evaluation of fuel element materials and manufacturing processes. Prototypical CERMET fuel elements with integral flow channels and complex geometries have been successfully fabricated to net shape. Material properties are also being evaluated to determine fabrication limitations and feasible design concepts. The goal is affordable development to help validate requirements and minimize technical, cost, and schedule risks prior to committing funds for expensive testing.

\section{References}

${ }^{1}$ Koenig, D., "Experience Gained from the Space Nuclear Rocket Program (Rover)," LA-10062-H, May 1986

${ }^{2}$ Bhattacharyya, S.K., “An Assessment of Fuels for Nuclear Thermal Propulsion,” ANL-TD-TM01-22, December 2001.

${ }^{3}$ Haertling C., and Hanrahan R. J., "Literature Review of Thermal and Radiation Performance Parameters for High Temperature Uranium Dioxide Fueled CERMET Materials’, Journal of Nuclear Materials, 366 (2007) 317-335. 
Fabrication and Testing of

CERMET Fuel Materials for Nuclear

Thermal Propulsion

Nuclear Cryogenic Propulsion Stage (NCPS)

Advanced Exploration System (AES) Project 8 


\section{Outline}

- AES Nuclear Cryogenic Propulsion Stage (NCPS)

- CERMET Materials and Processes

- W-UO2 feedstock

- Plasma spheroidization

- CVD tungsten coated UO2

- Hot Isostatic Press (HIP) fabrication of fuel elements

- Hot Hydrogen Testing

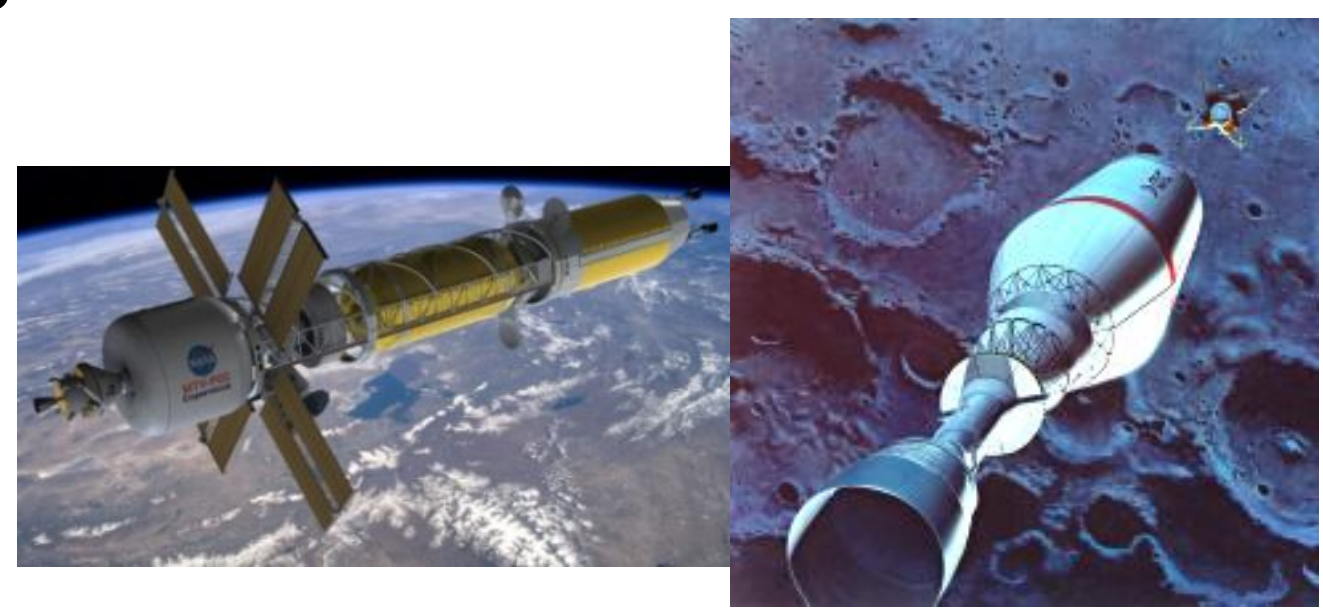




\section{Nuclear Cryogenic Propulsion Stage (NCPS)}

- NCPS started in FY2012 to assess affordability and viability of NTP

- NTP is a game changing technology for space exploration

- 800-900 sec ISP

- Overall tasks

- Pre-conceptual design and architecture integration

- Fuel Design and Fabrication

- Nuclear Thermal Rocket Element Environmental Simulator (NTREES)

- Affordable Development and Qualification Strategy

- Second Generation Concepts

- Critical need for fuels development

- Lack of qualified fuel material is a key risk

- Development of stable fuel form is a critical path, long lead activity

- Fuel task objectives are to demonstrate capabilities and critical technologies using full scale element fabrication and testing

- Enable future fuel optimization

- Buy down risk for future fuel development and ground test demonstration 


\section{NCPS Task 4: Fuel Design and Fabrication}

- Needs

- Develop and down select robust fuels

- Validate affordable fuel development and qualification plan

- Goals

- Mature CERMET and Graphite based fuel materials

- Develop and demonstrate critical technologies and capabilities

- Objectives

- Develop W-UO2 CERMET fuels and fabrication capability

- Recapture graphite composite fuels and fabrication capability

- Characterize fuel microstructure, material properties, and performance in hot hydrogen environment

- Perform full scale element testing of CERMET and graphite fuels

- Highly integrated NASA/DOE fuels development team

- Enhance and utilize existing infrastructure and capabilities 


\section{What is a CERMET Fuel?}

- CERMET fuels consist of a metal matrix with embedded ceramic fuel particles

- W matrix (high melting point, $\mathrm{H} 2$ compatibility)

- UO2, UN, (U,Zr)CN fuel particles

- Developed in 1960's as an alternate to graphite based fuels

- Long operating life (>10 hrs, 2800k)

- Multiple restart capability at high specific impulse (800-900 sec)

- Improved fission product retention

- Metal phase improves toughness
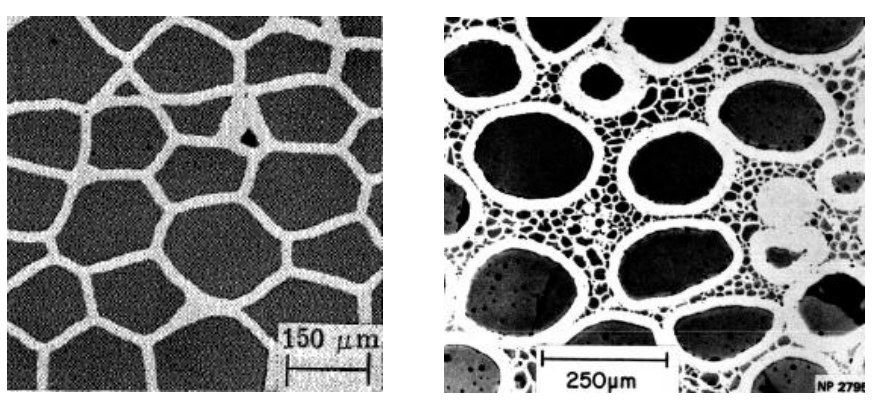

W - light phase, UO2 - dark phase

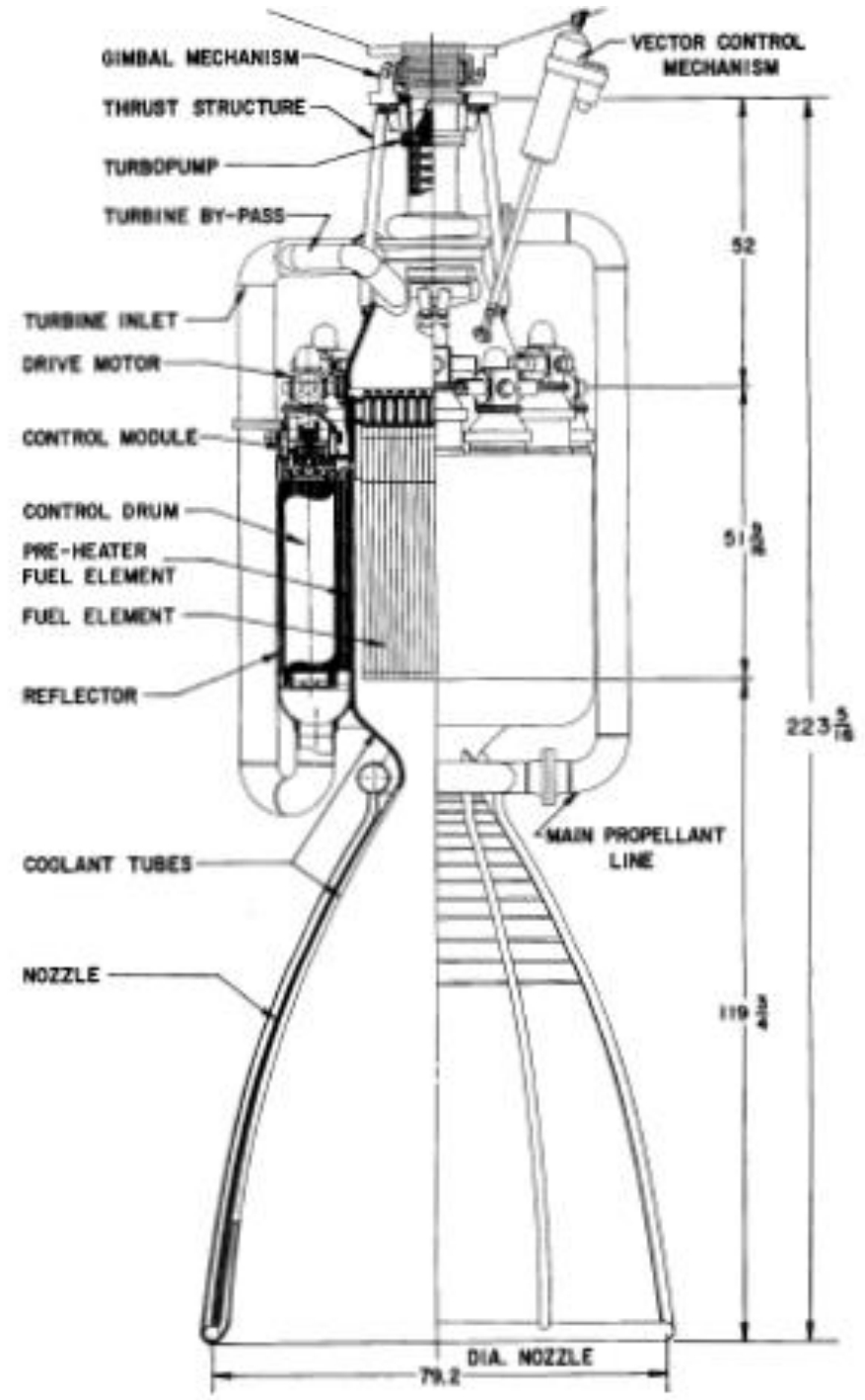

ANL 2000MW CERMET Engine 
- Demonstrated but not proven to full scale

- ANL, GE710, NASA GRC

- Minimal fuel loss at $2770 \mathrm{~K}$ in $\mathrm{H} 2$

$-<1 \%$ loss, 180 cycles, 45 hours

- Establish fabrication processes

- Hot Isostatic Press (HIP)

- Pulsed Electric Current (PEC)

- Baseline material properties

- Tensile, thermal, and fatigue/fracture

- Assess performance in hot hydrogen

- Develop Irradiation plan

- Define needs for down select

- Evaluate capabilities/options

- Need to understand cost vs risk

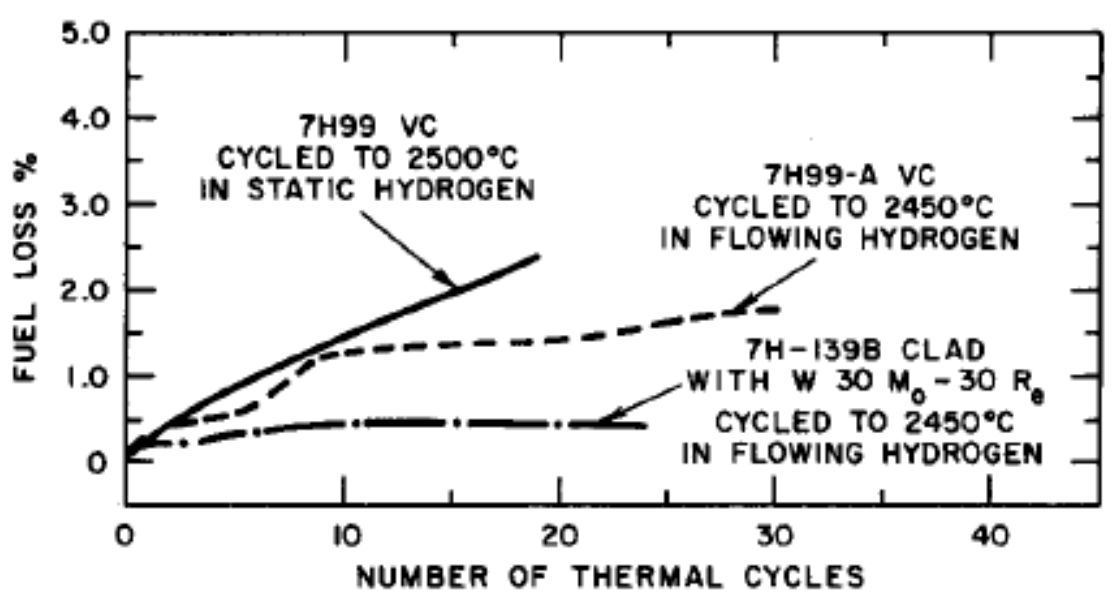

THERMAL CYCLING CONDITIONS 2-60-5 2-15-5 [2500 0 C $], \ldots$ IN DRY HYDROGEN

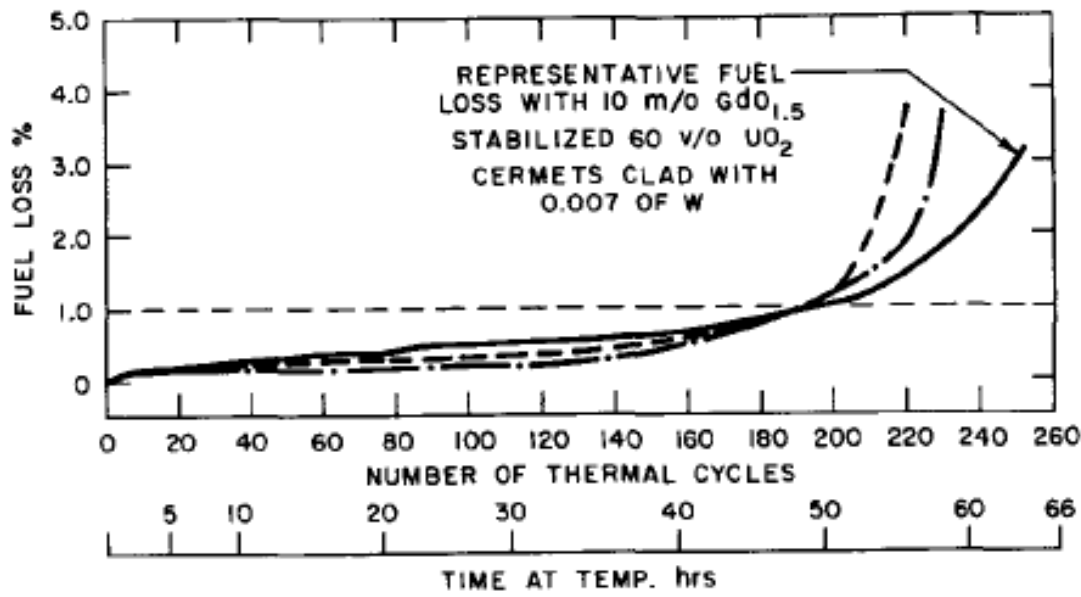

ANL Program Hot H2 Test Data 


\section{W-UO2 Materials and Process Development}

- Development based on previous programs

- Fuel loss mechanisms for W-UO2 CERMETS

- Vaporization of exposed/interconnected UO2

- Thermal decomposition of fuel/matrix

- Diffusion through pores and cracks

- Differences in CTE of W matrix and UO2

- M\&P approaches that inhibit fuel loss

- Size of UO2 and shape in the consolidated part

- W coated spherical UO2

- Complete surface cladding with tungsten

- Addition stabilization materials

- Iterative approach to sequentially demonstrate M\&P and optimize fuel materials

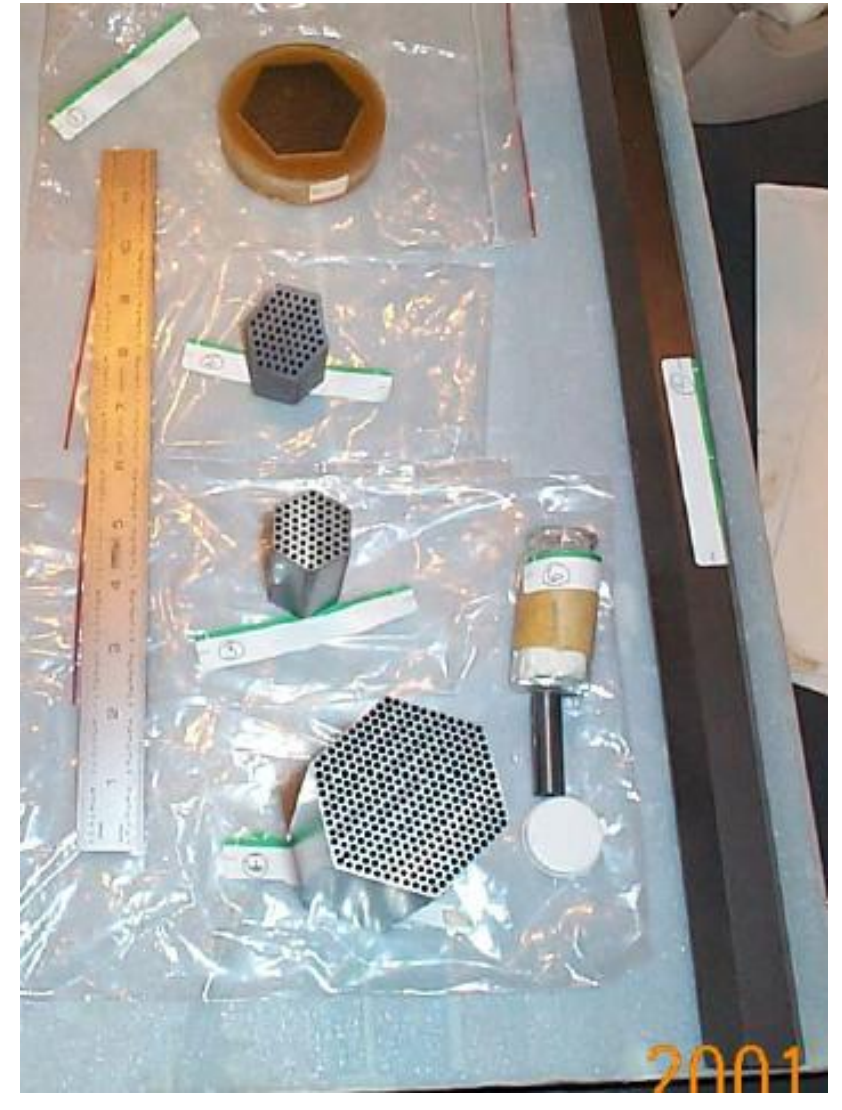

W-UO2 CERMET Samples fabricated during ANL Program 


\section{Develop W-UO2 Feedstock}

- Quality UO2 feedstock is critical

- Size, shape, and purity

- No specific requirement for UO2 particle size

- Previous programs suggest 10-200 $\mu \mathrm{m}$

- Spherical particles provide improved properties

- Spherical UO2 is available from ORNL, BWXT

- Very high cost $\$ \$ \$$, >100 um

- Readily available UO2 from Y-12 at low cost

- Angular particle shape

- Plasma Spheroidization System (PSS)

- Particles partially melted in plasma, re-solidify in spherical shape, and collected in chamber

- MSFC has rich history in plasma spray coatings

- Dedicated Thermal Spray Laboratory

- PSS operational check is complete

- $\mathrm{CeO} 2$ trials beginning in early August

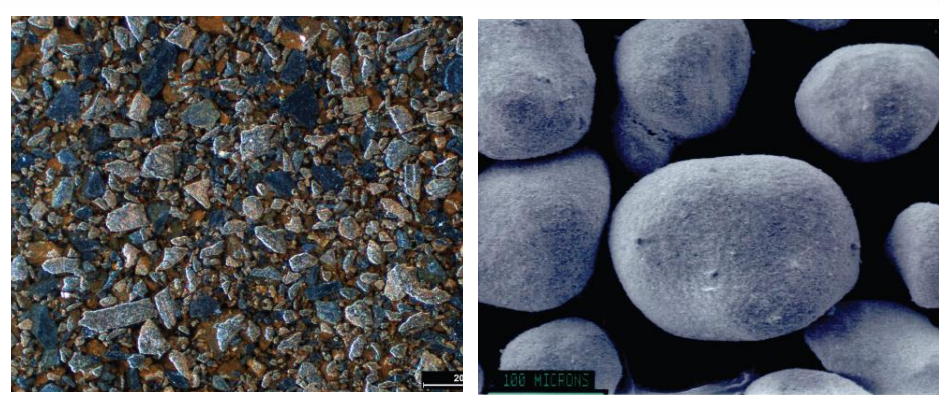

Micrograph of angular UO2 particles

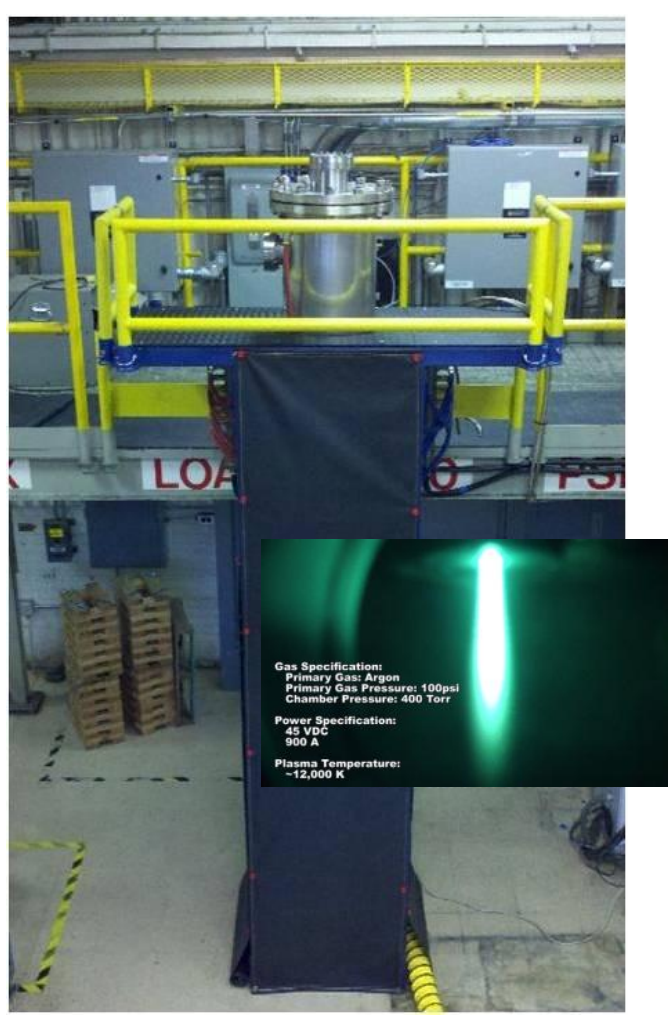

Plasma Spheroidization System (PSS) 


\section{CVD Tungsten Coated UO2}

- W coated UO2 particles are required to improve properties and minimize fuel loss

- Clearly demonstrated on previous programs

- Prevents particle contact and agglomeration

- Fluidized bed Chemical Vapor Deposition (CVD)

$-\mathrm{H} 2$ reduction of $\mathrm{WCl} 6$

- Multiple system design iterations

- Reactor, expander, sublimator, and feed system

- Demonstrated W coating on $\mathrm{ZrO} 2$

- Currently optimizing reactor and sublimator

- Requires sublimation of granular WCI6

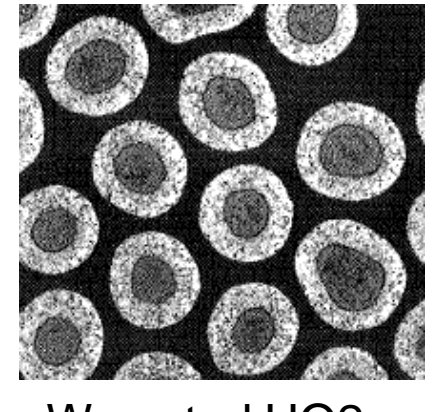

W coated UO2 (GRC, 1965)

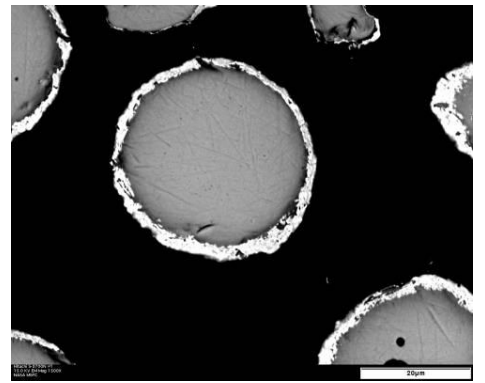

$\mathrm{W}$ coated $\mathrm{ZrO} 2$ (MSFC)
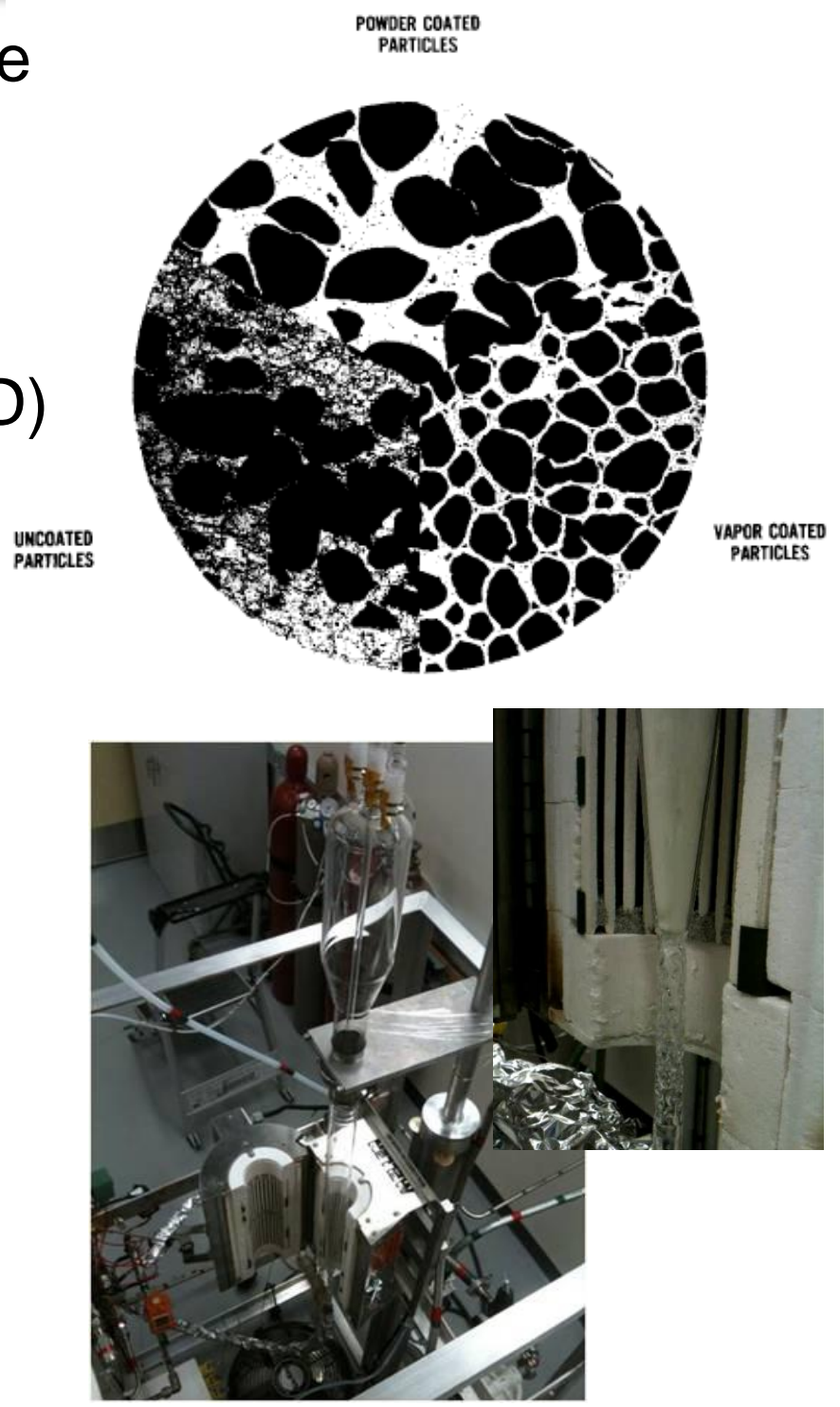

MSFC Fluidized Bed CVD System 


\section{CVD Process Optimization}

- CVD Reactor Modeling

- Multi physics (fluid flow, heat transfer, chemical reaction, particle fluidization, deposition etc.)

- Sublimation trials

- Measure critical process parameters

- Optimize temperature and rates

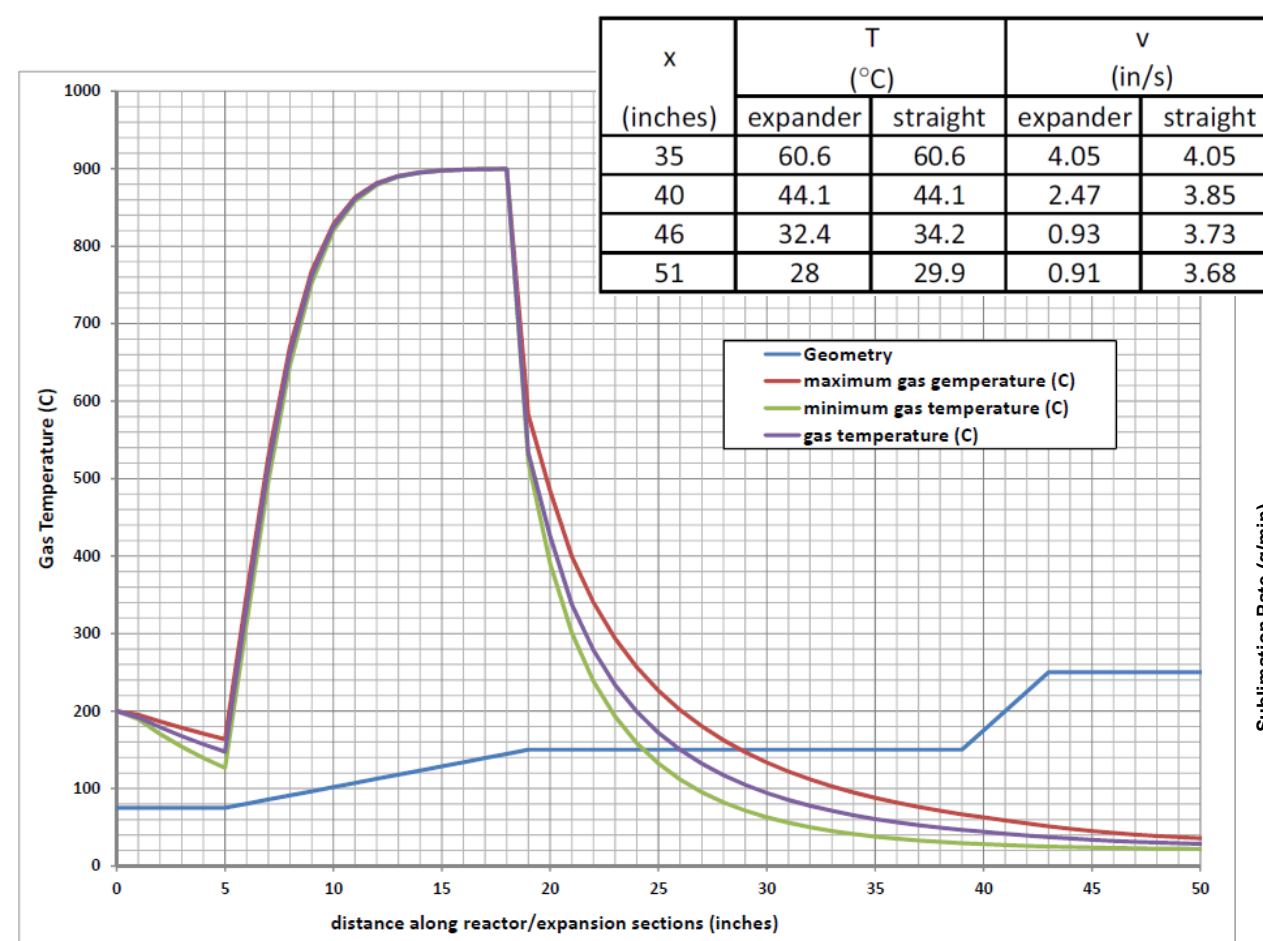

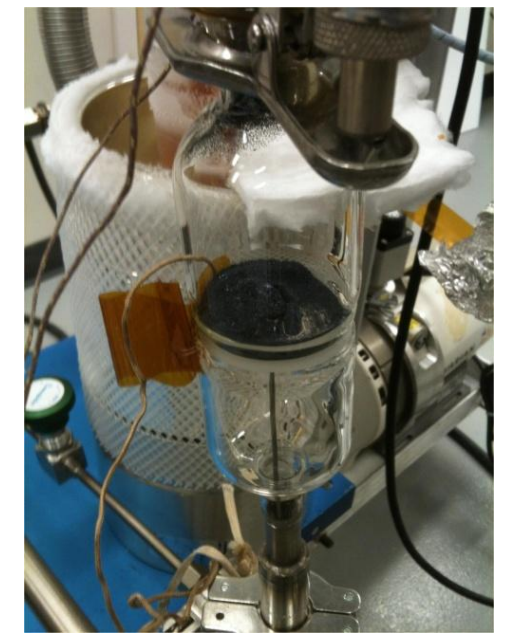

WCl6 sublimer

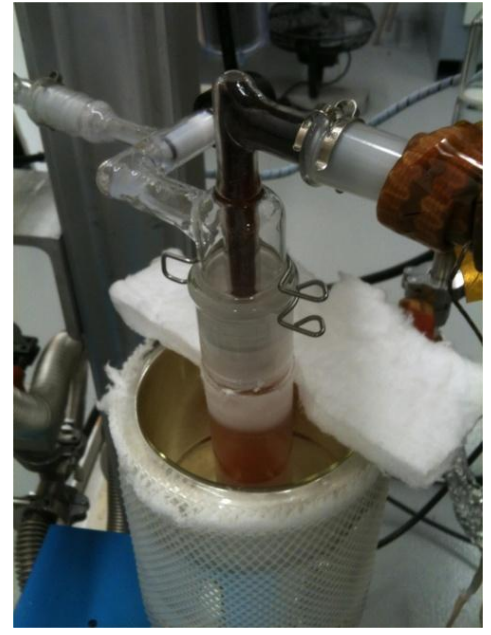

LN2 cold trap

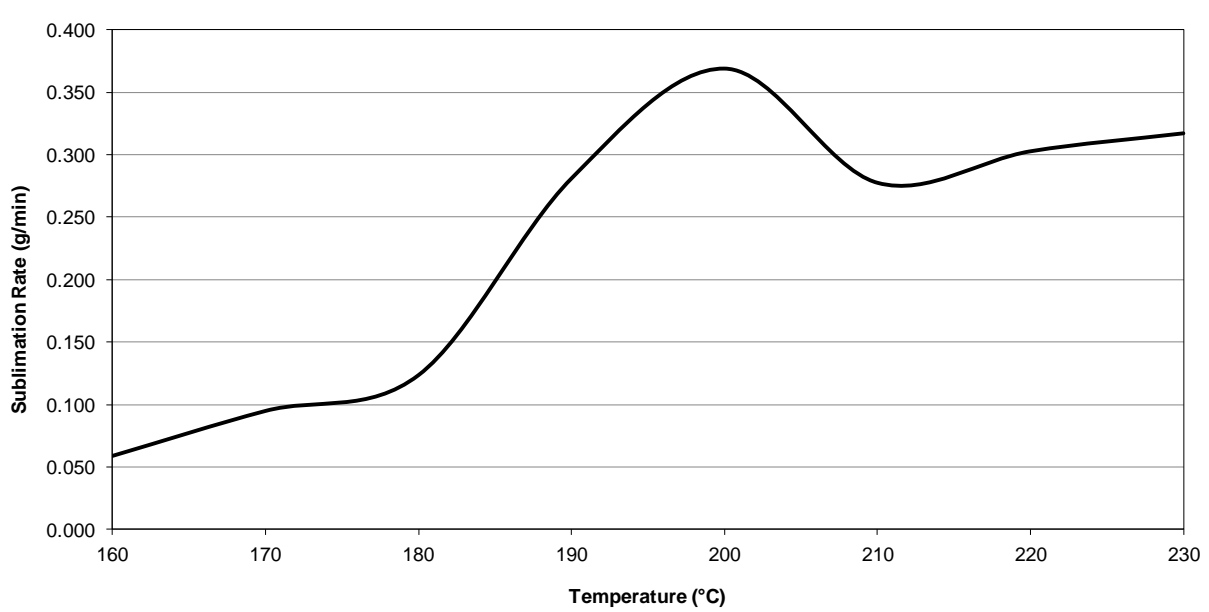

Gas temperature through reactor/expansion sections Gas is flowing from left to right 


\section{W-UO2 Consolidation Processes}

- W-UO2 feedstock must be consolidated into high density fuel elements

- Materials are very difficult to form using conventional techniques

- Processes demonstrated on previous programs do not currently exist

- No qualified fuel materials or processes

- Infrastructure from 1960's does not exist

- Must recapture critical capabilities

- Need to establish feasible fabrication processes prior to in depth optimization

- Materials are very sensitive to processing

- Processing and handling of UO2 is costly

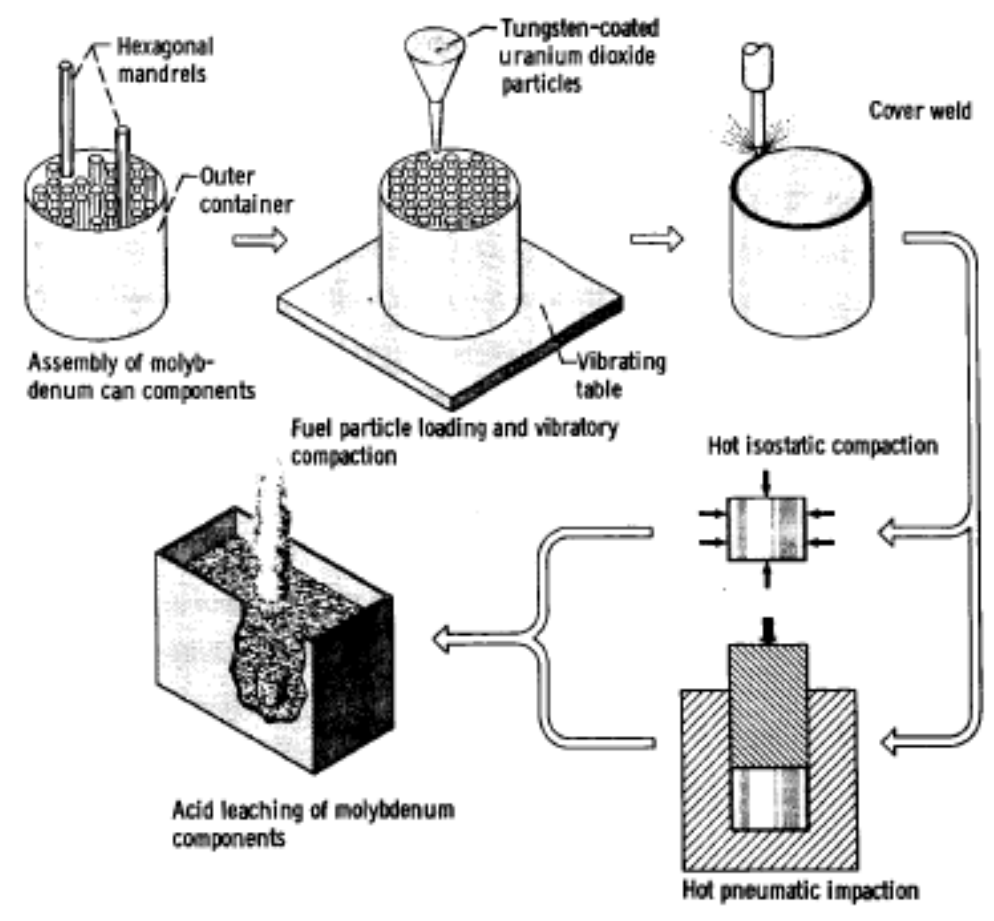

Hot Isostatic Pressing (HIP) and Hot Pneumatic Impaction

- Enables affordable future fuel optimization

- Minimize testing of UO2

- Mature material specifications and requirements 


\section{Hot Isostatic Press (HIP) Consolidation of W-UO2}

- Demonstrated at MSFC using in-house capability

- >99\% density, complex shapes

- Integral channels and claddings

- HIP system operational in Sept 2012 (8" ID, 30" Long)

- Completed fabrication of ANL 2000MW sample

- 331 channel hexagonal element
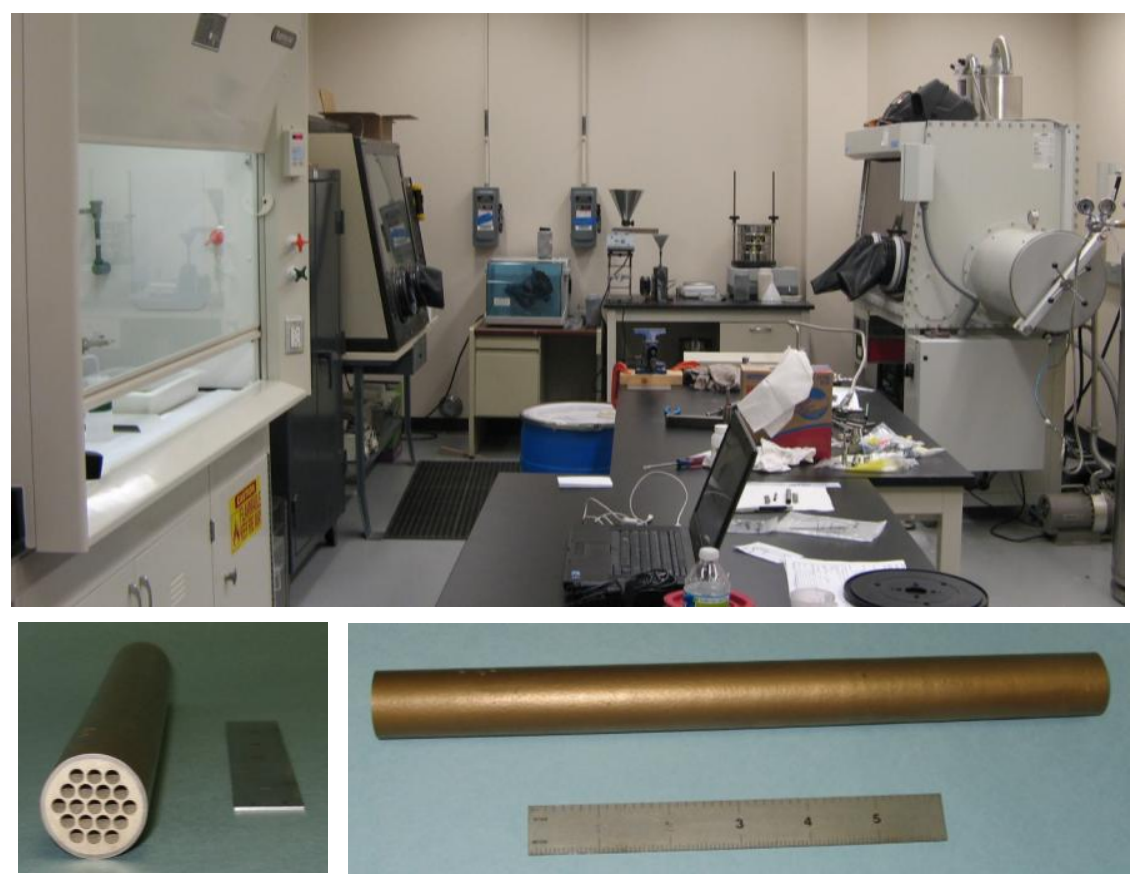

W-HfN CERMETs (19 channels, 1" diameter x 2" and 12" long)

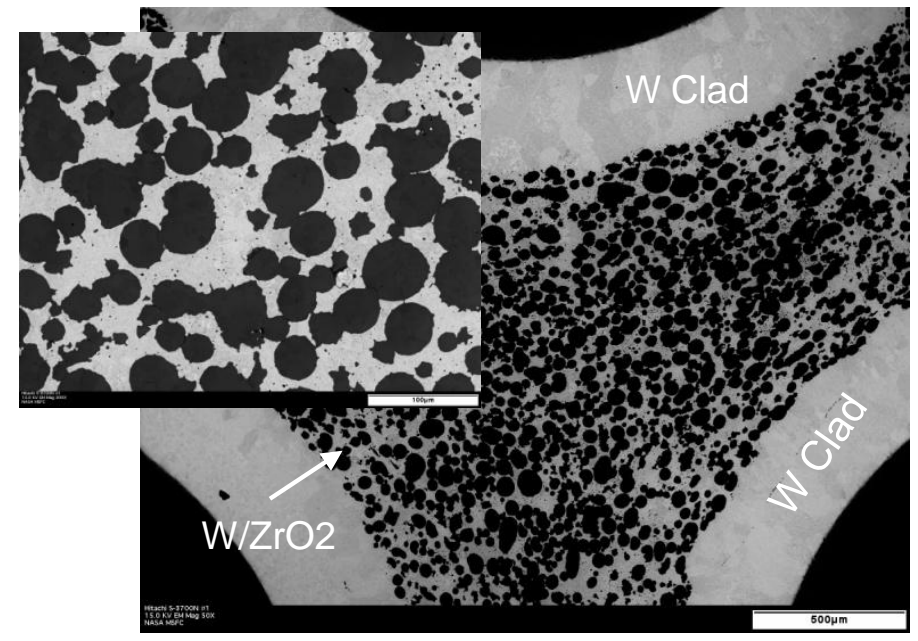

Fabrication of CERMETS by HIP 


\section{HIP Fabrication of Prototypic Fuel Elements}

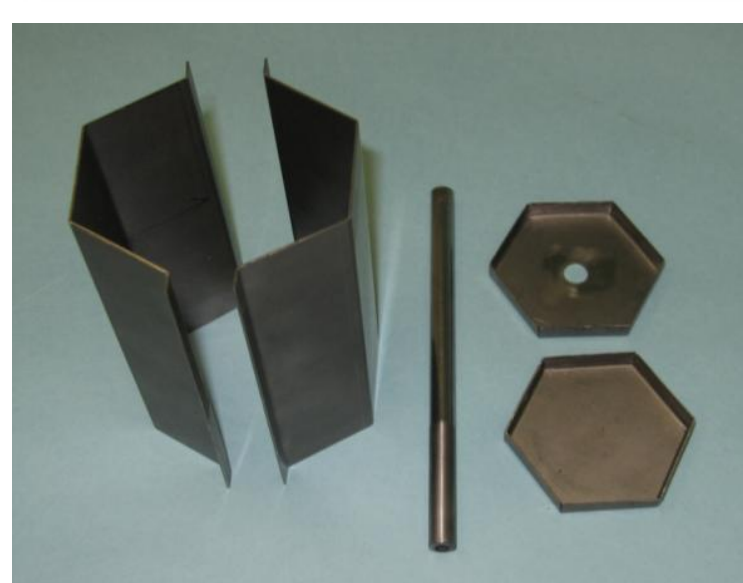

Hexagonal HIP can components

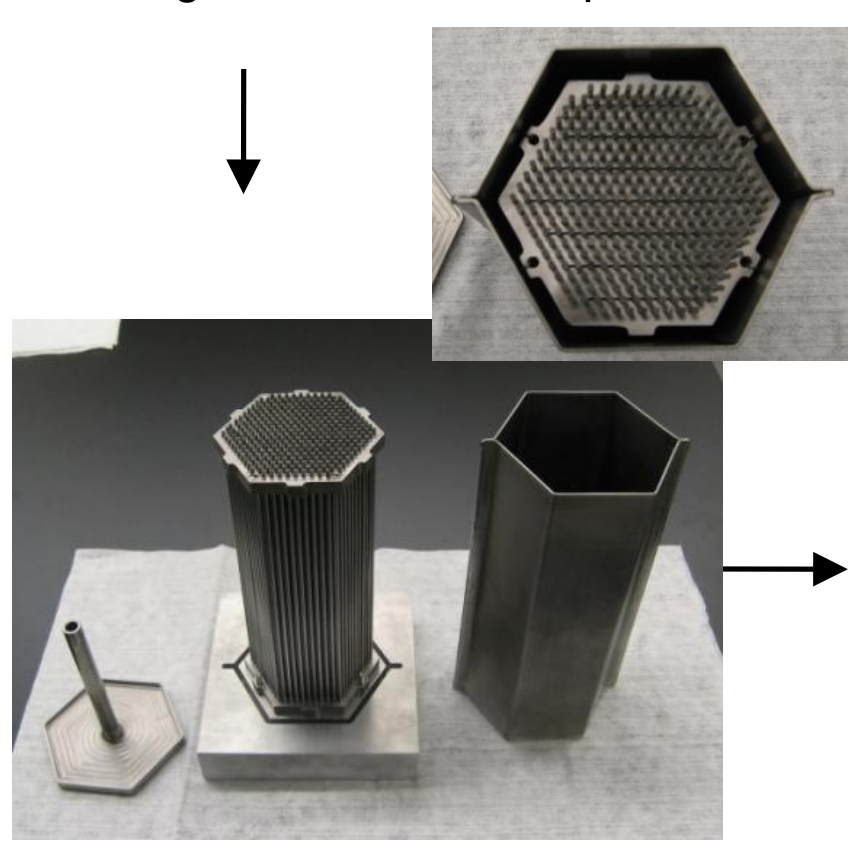

Mo Mandrel assembly

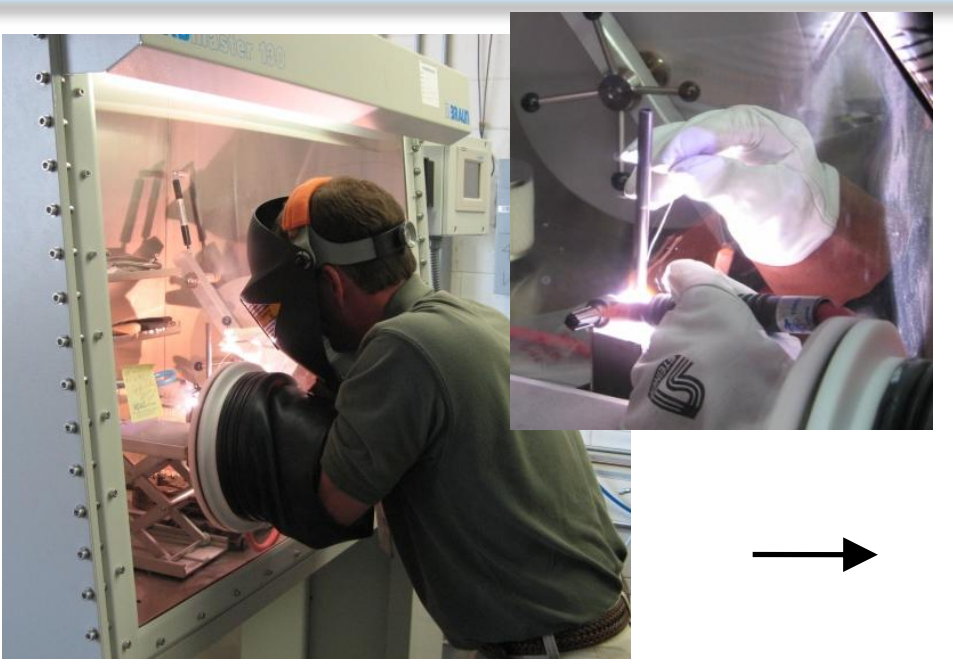

Final closeout weld

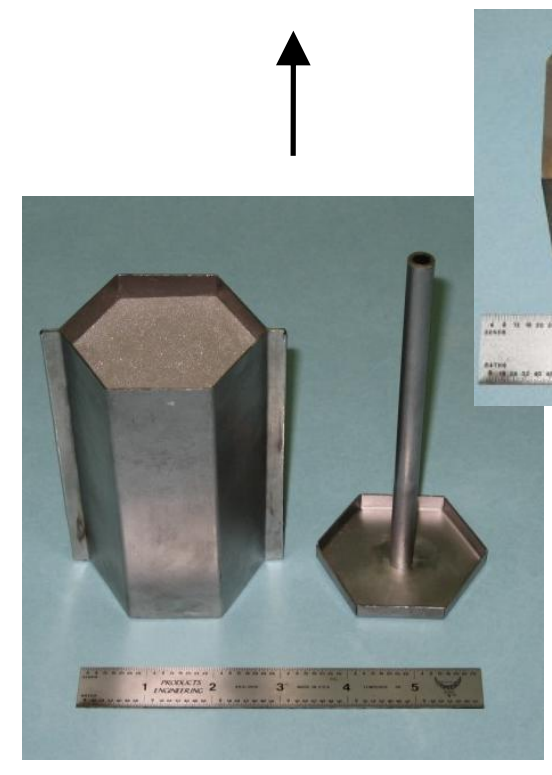

HIP can after powder fill

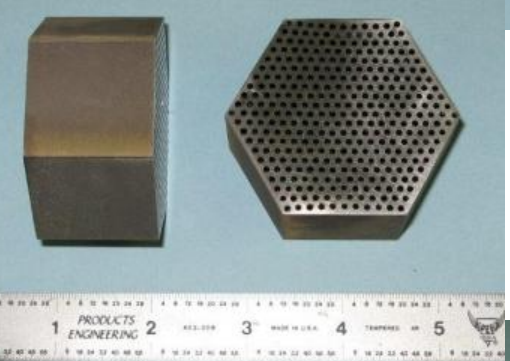

Sealed HIP Can

1

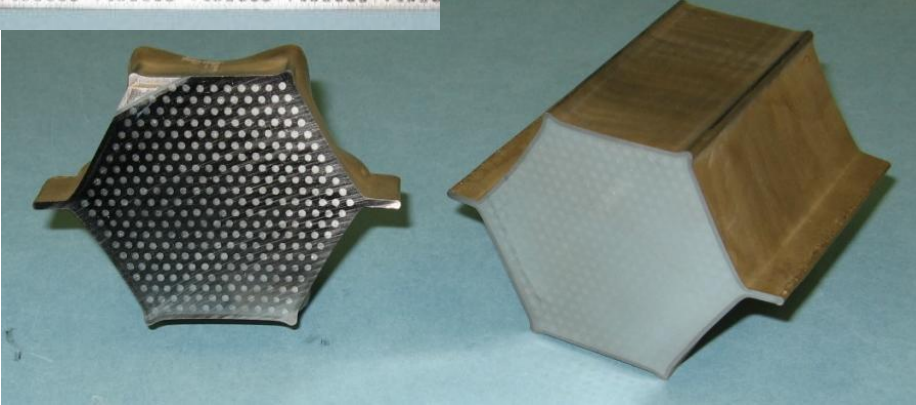

Can assembly after HIP cycle 


\section{Current Status of HIP Fabrication Development}

- Parameter study using $\mathrm{W}$ and $\mathrm{ZrO} 2$ powders

- Particle size varied to evaluate initial packing density, shrinkage and agglomeration

- Time and temperature varied to evaluate tungsten density and grain size

- Critical need for W coated particles for optimization

- $3^{\text {rd }}$ generation hexagonal HIP can assembly

- Improved mandrel assembly

- Increased length (full scale 16.8" elements)

- 7-Hole test sample configuration (0.5" OD, 1" long)

- Based on ANL 200MW design

- Optimizing gloveboxes for processing of UO2

- Powder filling and can closeout
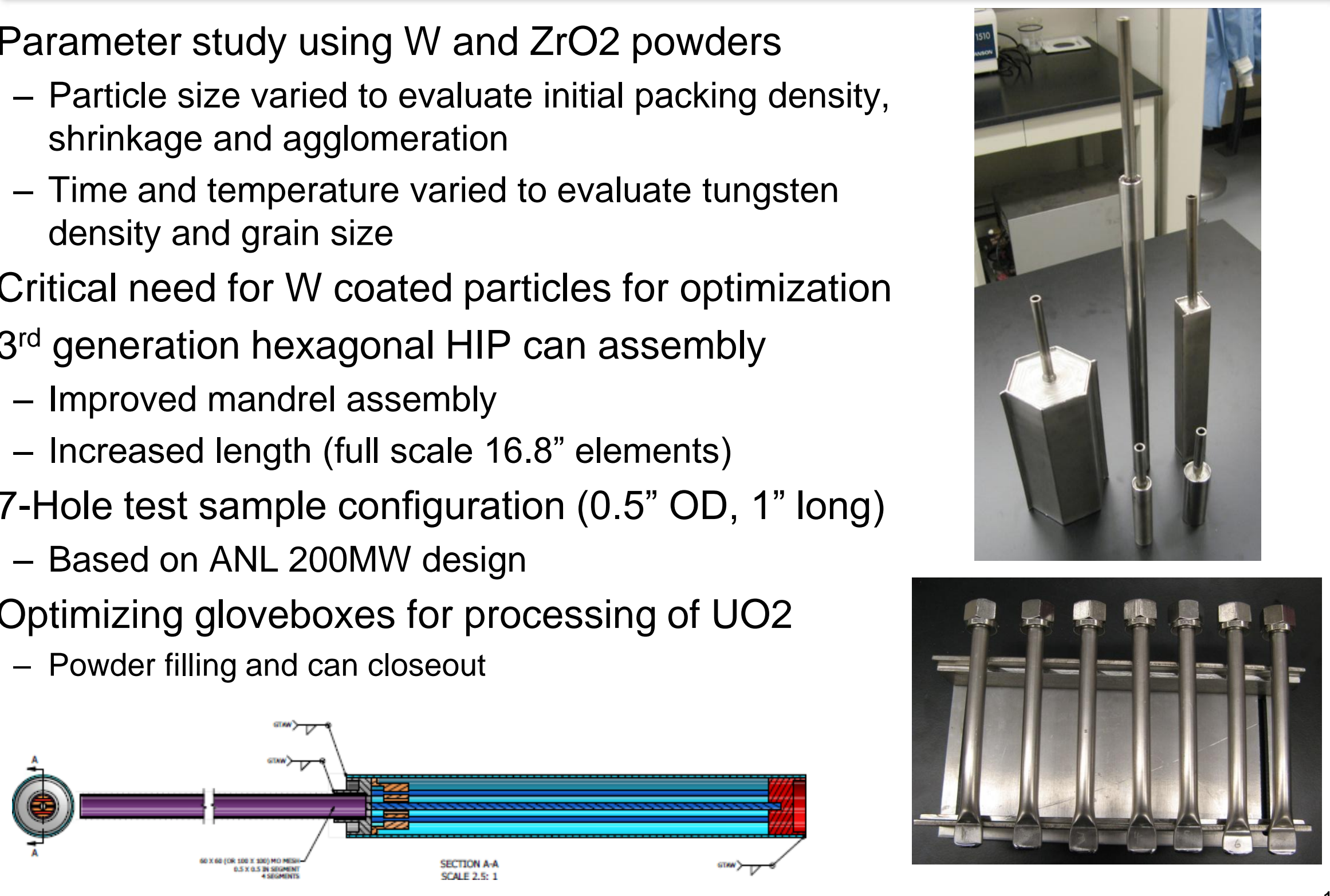


\section{Hot Hydrogen Testing}

- Critical need for screening of fuel materials in H2 environment

- Need flexible laboratory scale test system

- Materials and process screening

- Compact Fuel Element Environment Test (CFEET)

- Rapid testing of subscale samples (0.5" OD x 1-6" length)

- Planned CERMET fuel development testing

- Evaluate process, particles size, claddings, and stabilizers

- Static and flowing H2 (solid rod and 7 hole samples)

- NTR Element Environmental Simulator (NTREES)

- Testing of full scale elements in prototypical environment
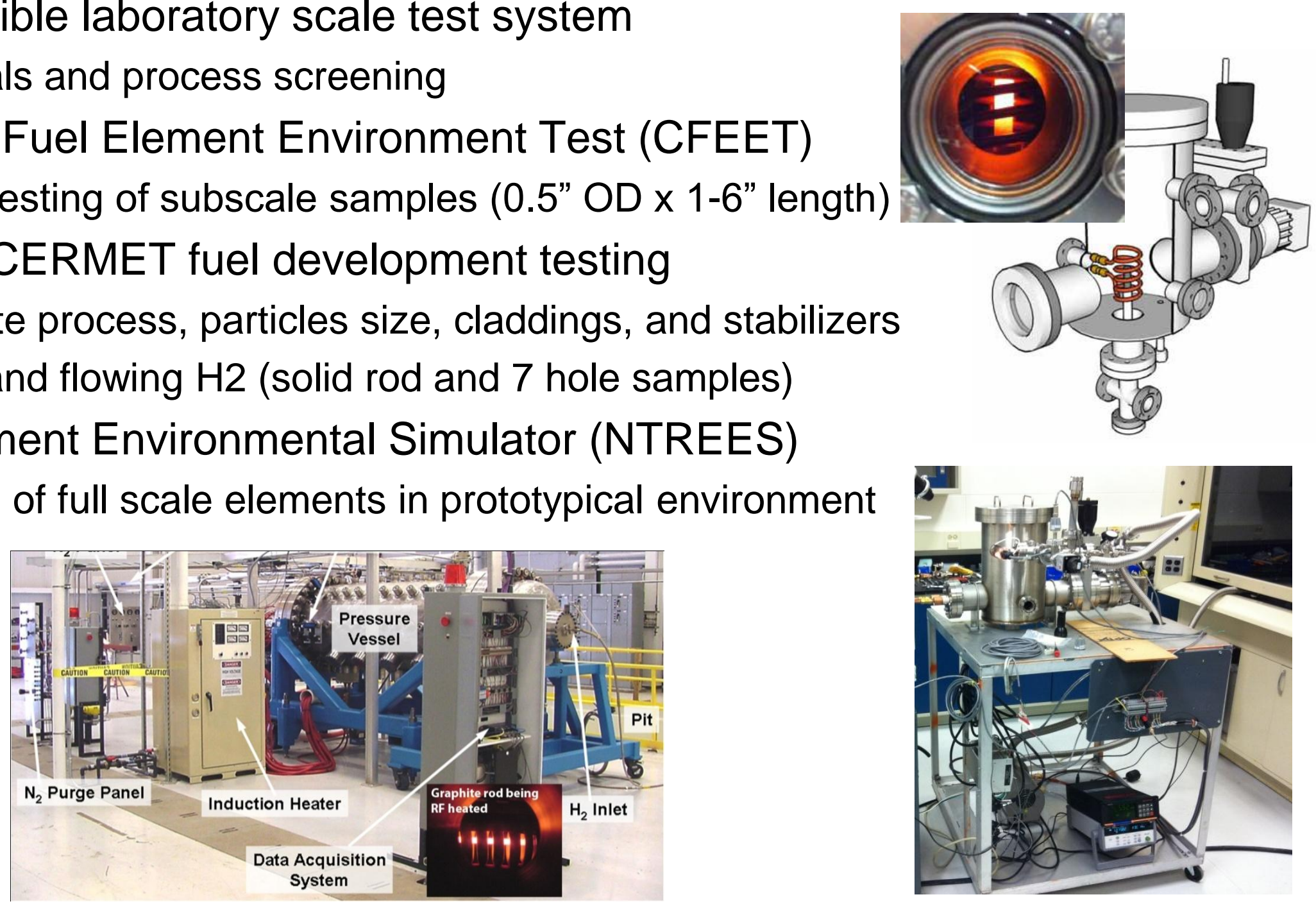


\section{CFEET Optimization and Verification}

- Numerous system modifications made to maximize temperature

- Vacuum, cooling water, RF coil, data acquisition, $\mathrm{H} 2$ feed, and sample support

- Operational tests using W-Re-HfN CERMET

- Tested to failure at 2565C (2838K)

- Evaluated ceramic insulators

- Reduce thermal radiation loss

- Currently integrating flowing hydrogen

- Analysis shows final system capable of $>3000 \mathrm{~K}$
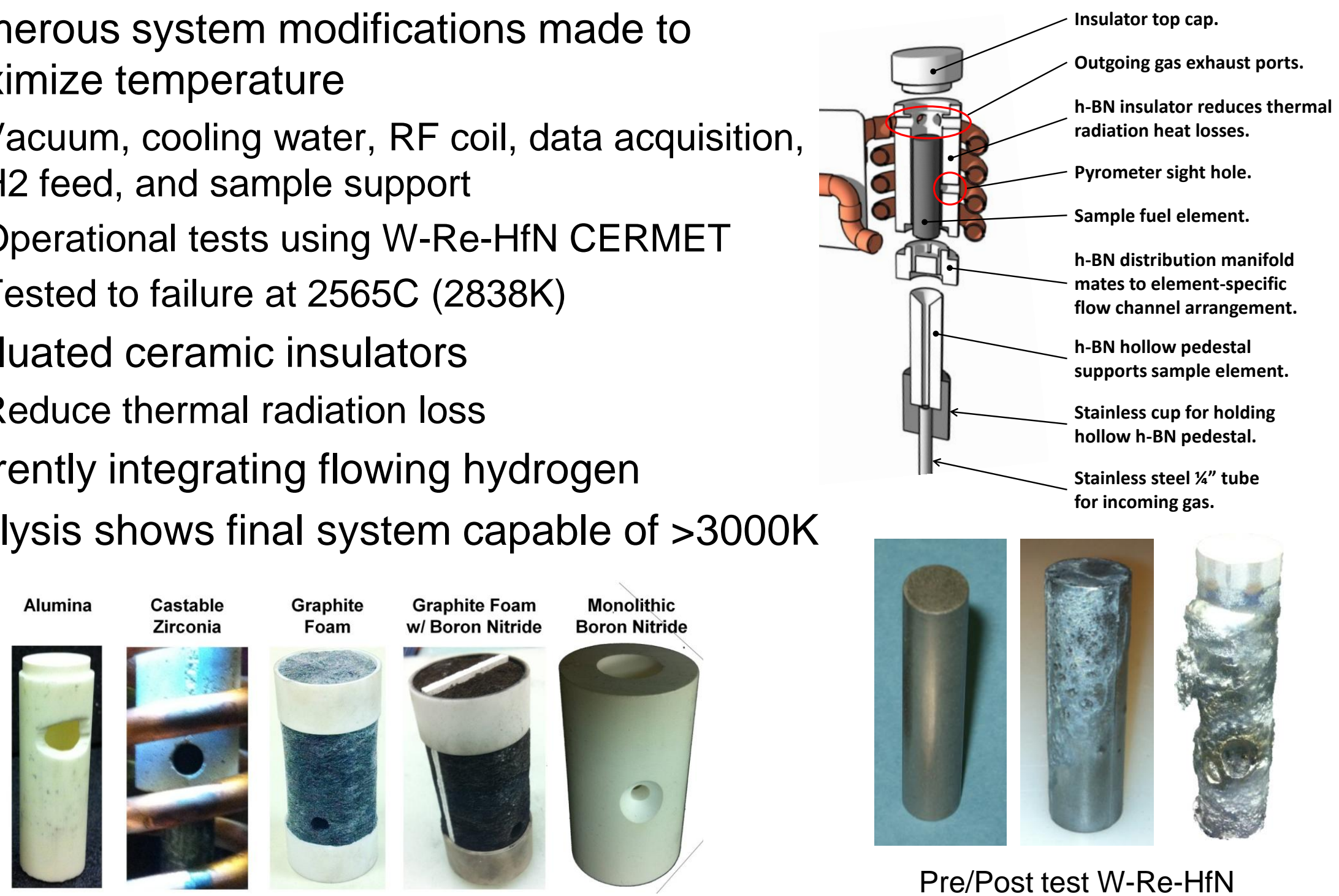

Pre/Post test W-Re-HfN CERMET samples 


\section{NTREES System Demonstration}

- Surrogate W-HfN sample fabricated by HIP

- Verify temp, instrumentation, $\mathrm{H} 2$, and sample fixtures

- 0.5" dia. x 12" long, 7 cooling channels

- Nb can was not removed due to non-uniform shrinkage

- Completed over two full Mars DRA5 mission profiles

- 3 hours, 8 cycles at $2073 \mathrm{~K}$

- Sample cracked during testing

- Uneven distribution of HfN particles (poor strength)

- Cracking due to embrittlement of the $\mathrm{Nb}$ and CTE mismatch

- Induced structural loads from test fixture

- Thermal gradient along the length of the element

- Need to evaluate test environment (thermal/mechanical stress)

- Iterative improvements required through testing and design to validate NTREES capability

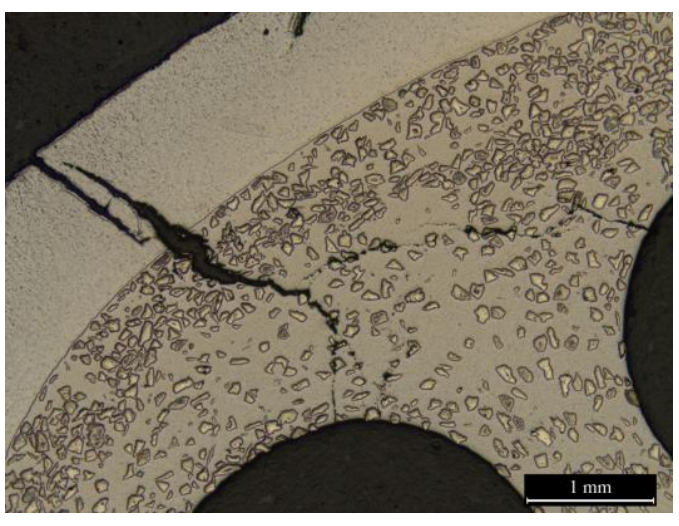

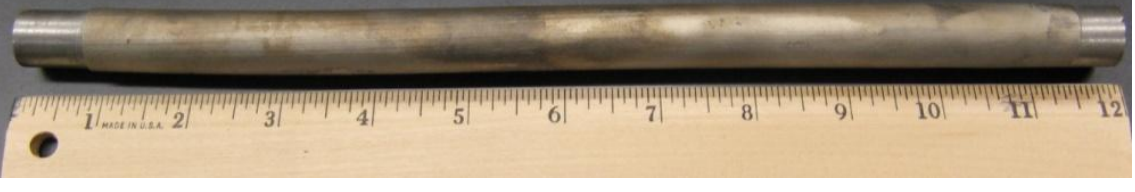

Etched and machined sample pre-test
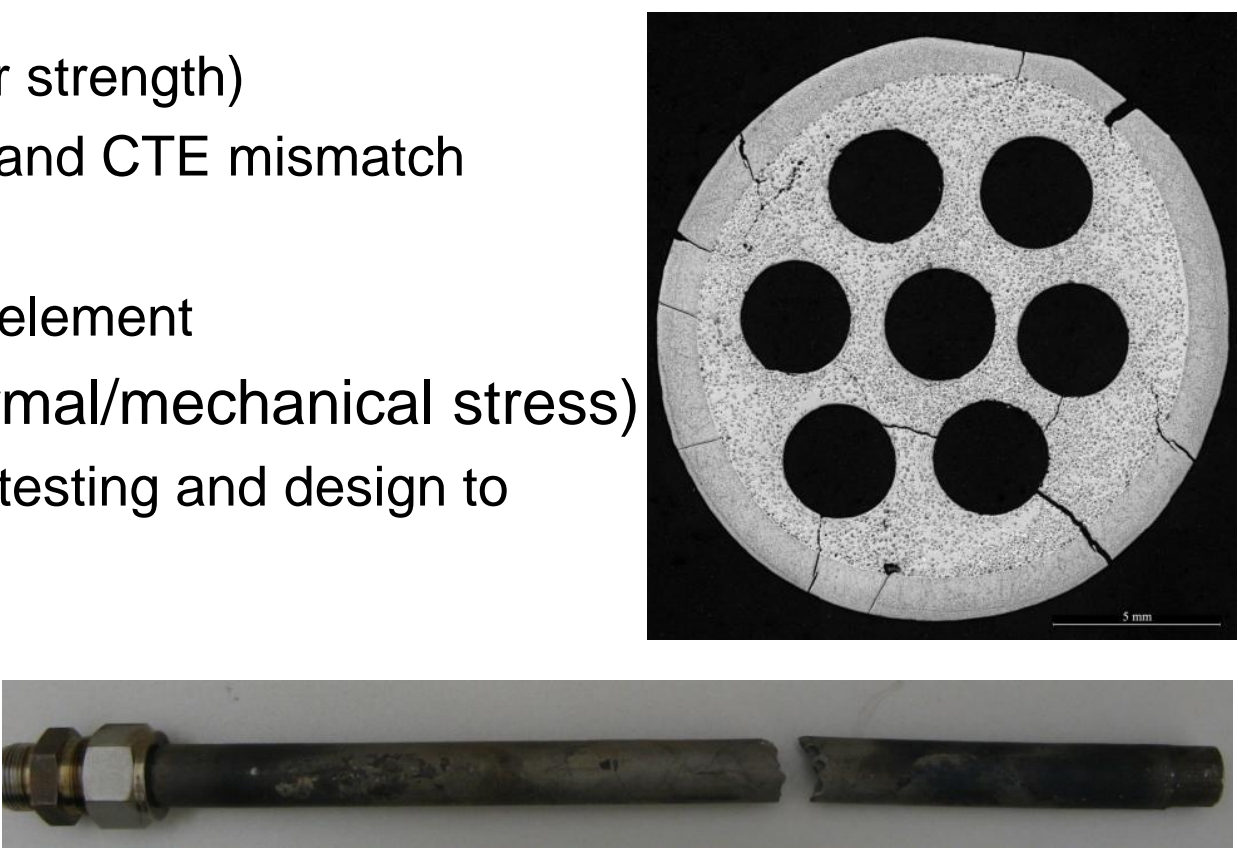

NTREES sample post test 


\section{Conclusions}

- AES project offers a unique opportunity to develop critical NCPS capabilities and technologies

- Highly integrated NASA/DOE fuels development team

- Maximizing use of existing NASA/DOE facilities and infrastructure

- Critical need for materials and process development

- UO2 feedstock

- CVD W coated UO2 particles

- Prototypical element manufacturing

- MSFC demonstrated HIP fabrication and testing of CERMET materials

- Rapid capability development using "proven" materials and processes

- Dedicated Laboratory for processing of depleted uranium

- Subscale hot hydrogen testing capability exist to screen W-UO2 fuels

- Processes, composition, particles size, claddings, and stabilizers

- Full scale element fabrication and test to validate fuel materials

- Enables future affordable, fuel optimization and down select 